\title{
Linking expected mobility production to sustainable residential location planning: some evidence from
}

\section{Flanders}

\author{
Kobe Boussauw $^{\mathrm{a}, \mathrm{b}}$ and Frank Witlox ${ }^{\mathrm{a}}$ \\ ${ }^{a}$ Geography Department, Ghent University, Krijgslaan 281/S8, 9000 Gent, Belgium \\ Tel.: +32926445 55 - Fax.: +329264 4985 \\ E-mail: kobe.boussauw@ugent.be; frank.witlox@ugent.be \\ ${ }^{\mathrm{b}}$ corresponding author
}

\begin{abstract}
Based on a set of spatial proximity characteristics this paper develops a model that estimates for every neighbourhood in Flanders (Belgium) the amount of traffic that would be generated by an additional residential unit when socioeconomic variables are held constant. The results show that residential density, land use diversity and proximity of facilities influence daily travelled distances when these variables are measured in the immediate vicinity of the residential location of the respondent (within a radius of $1 \mathrm{~km}$ ). When aggregating these variables at a larger geographical scale, in most cases the impact proves no longer significant. Variables based on the spatial distribution of jobs, or on the global accessibility of the entire population in the study area, do not show any significant effects on the travel distance.

Despite the statistical significance only a fraction of the observed variance in reported distances is explained by characteristics of spatial proximity. However, we can assume that the importance of spatial structure in the genesis of mobility patterns will increase in case the cost of transport would rise (cf. peak oil). For this reason, the application of the mapped results of the proposed model could contribute to the practice of sustainable spatial planning.
\end{abstract}




\section{Research highlights}

- Land use features that influence distances travelled are determined for Flanders.

- Spatial distribution of jobs does not determine general trip patterns significantly.

- Local spatial proximity should play a role in housing development planning.

- Adequate planning allows for travel behaviour adaptation under rising energy prices.

\section{Keywords}

spatial proximity, travel behavior, sustainable spatial development, Flanders

\section{Introduction}

Research into the relationship between spatial structure and travel behaviour exists in many forms. Scholars typically focus on the search for statistical associations between aspects of travel behaviour (such as choice of mode or destination, travel time or trip length) and spatial characteristics (such as density and degree of mix of homes, jobs and other facilities, or mere morphological features such as street patterns and neighbourhood layout). Ewing and Cervero (2010) present an extensive literature review on this.

An important part of the existing research in this field focuses on the potential application of the obtained results in the development of a more sustainable urban and regional spatial structure that can operate on the basis of minimal energy needs for transport (Ewing et al., 2008). Although many policy plans still refer to Newman and Kenworthy $(1989,1999)$, who argue that there is a strong inverse relationship between population density and transport energy consumption per capita, later research shows that this statement is a serious simplification. Criticisms of Newman and Kenworthy (1989, 1999) (Mindali et al., 2004; Mees, 2010, pp. 24-26) rely mostly on methodological issues, such as the chosen demarcation of the studied cities, while quantitative research into the relationship between spatial characteristics and energy consumption in a regional network structure finds much more complex interactions (Boussauw et al., 2011a). Energy consumption by transport is partly 
determined by the modal split, and partly by the total distance travelled within the studied system. Previous research shows that in regional studies (which go beyond the urban scale), in a western context, the daily distance travelled per person is a good approximation of sustainability of travel patterns (Boussauw and Witlox, 2009), while the influence of modal split is only secondary. In the following sections, we will therefore focus on the relationship between distance travelled and land use characteristics that measure mutual proximity between possible destinations.

In this over the years adequately documented line of research, we can distinguish two important constants: i.e., (i) the assumed relationships always appear to be statistically significant, but (ii) explain only a small share of the observed variance. The first of these two findings is actually trivial: it would be quite remarkable if the influence of the spatial distribution of different types of destinations, which among others defines mutual distances that need to be covered, would not pass significance tests (Naess, 2003). The second finding, however, is a lot less comforting: the explained variance (in many analyses represented by the coefficient of determination $\left(\mathrm{R}^{2}\right)$ of a regression equation) is usually very low (Handy et al., 2005a; Cervero and Kockelman, 1997; Cervero, 1996; Naess and Sandberg, 1996). Obviously, this means that spatial characteristics explain travel behaviour to an only very limited extent.

In socio-geographically inspired research, spatial features are usually only one of the considered clusters of explanatory variables in the model. By combining many sociodemographic and economic variables (such as income, car ownership, family composition, lifestyle or job preference) with spatial characteristics, a relatively satisfactory fit may be obtained (Van Acker and Witlox, 2011; Maat and Timmermans, 2006). An advantage of this approach is the accurate estimation of the model coefficients since the influence of any potential correlation between spatial and socio-economic variables is filtered out. An example of such a correlation is the inverse relationship between income class and residential density. A major drawback of upgrading a spatial model to a socio-economic model to explain travel behaviour is that the influence of the spatial structure, which is present anyway, seems to fade into the background.

A model built on mere spatial features is nevertheless useful for spatial policy. Although spatial characteristics explain only a small part of the assessed travel 
patterns, the built environment is still determining the physical preconditions for sustainable mobility patterns. Moreover, we argue that the importance of the spatial component in the genesis of travel patterns is not constant throughout history, but is linked to the cost and the speed of mobility. Over the centuries, the absolute cost to move an individual over a distance of one kilometre has almost continually been decreasing, if we neglect the slight ripples in the cost curve during the oil crises in the seventies. Moreover, the average speed of travel has been continuously increasing world wide (Schafer, 2000), a phenomenon that is largely explained by the growth in car ownership and the extension of the road network. Both developments have led to a systematic decline of the importance of physical distance between potential destinations (Rietveld, 2004), which in turn resulted in the weakening of the transport-land use connection (Giuliano, 1995). In statistical analyses based on spatial characteristics this phenomenon is reflected in a low coefficient of determination.

The continuing decline in transport costs is only possible through the abundant availability of energy in the form of fossil fuels and is therefore finite (Wegener, 2010). According to the peak oil theory (Witze, 2007) the relative cost of oil products may significantly increase over time, leading to a reduction in mobility and a growing importance of mutual spatial proximity of destinations (Dodson and Sipe, 2008). The proportionately small share of the variance in travel patterns that is explained by spatial structure should not be considered unimportant. It is exactly physical space that is the most rigid component, and thus the slowest to adapt to changing economic conditions, in contrast to e.g. behavioural elements that are more subject to an individual's choice.

The aim of the current research is the development of a model for the study area of Flanders (Belgium), based on mere spatial characteristics, that indicates what level of mobility production (expressed as daily distance travelled per individual) is associated with the location of an additional housing unit in a certain area. The use of the residential location as a reference for the study is taken by the abundance of available residence-based travel data. We use data from the 2007-2008 Travel Behaviour Survey for Flanders (Janssens et al., 2009) and a number of additional data sets containing spatial variables. 
In a first phase, the relationship between characteristics of spatial proximity, as measured in the area of residence, and individually reported daily travel distances is assessed through a linear regression model. The model accounts for variability related to the applied aggregation level by incorporating various geographical scale levels. In a second phase, results obtained from the regression analysis are used to construct a map which represents for each statistical ward the expected mobility production by an inhabitant in this location if only spatial variables are taken into account. Obviously, the model will explain only a limited share of the expected variance, an aspect which should be taken into account in the interpretation. This means that the applicability of the model is largely relying on the assumption that observed relationships may become stronger in the future.

Unlike the usual approach taken to the assessment of land use-transport connections, which aims to detect statistical relationships, our study expands the findings immediately to an application that is useful in location policy at a regional scale level.

\section{Study area}

The research focuses on the Flanders region, which is together with the Brussels Capital Region composing the north of Belgium. The main borders of the Flanders region are constituted by the North Sea, the Netherlands and the Walloon region (south of Belgium). The Brussels Capital Region, which has over one million inhabitants, is the largest agglomeration in the region, and is in geographical terms centrally located in Flanders.

In addition to Brussels, the metropolitan areas of Antwerp (400,000 inhabitants) and Ghent (250,000 inhabitants) are located in Flanders, as are ten regional cities (with a population of around 100,000 inhabitants) and a series of smaller urban centres and municipalities.

An interesting, typical Belgian, aspect is found in the history of the institutionalized commute, through government support for the construction of an extended railway network and cheap commuter tickets, aiming for the industrialization of the country based on a minimum of urbanization (Verhetsel et al., 2010). In the 19th century and 
early 20th century, this policy led to a clustering of housing and amenities in the towns and villages that were connected to the railway network. After World War II, these structures have fanned out into car-oriented suburban developments, an evolution that is associated with ever increasing mutual distances between homes, jobs and daily facilities, and has created a major source of dispersed traffic (Boussauw et al., 2011b).

\section{Methodology and data}

\subsection{Analysis and model structure}

The objective of the paper is to develop a model that forecasts regional variations in mobility production based on characteristics of spatial proximity at the residential location. We use regression analysis, with daily kilometrage per person as the dependent variable. Explanatory variables consist of a number of measures of spatial proximity that are observed at various aggregation levels around the individual residential locations. In addition, a number of socio-economic variables are used as control variables. The applied data sets are described below.

We start from a full model that includes all considered variables. Then, we trim the model and ultimately only retain those variables and scale levels that show statistically significant. If necessary, transformations are applied to address potential deviations from the normal distribution or prominent non-linear relationships.

After building and trimming the model, the obtained equation is used to estimate the mobility generating character of each neighbourhood (i.e. census ward) in Flanders. For each ward the relevant spatial variables are recalculated, from which the expected daily number of generated kilometres per person is regressed. These values are then displayed in the form of a map. When interpreting the map, it is important to realize that the extent to which spatial structure explains the mobility of a (new) resident of any area is indicated by the coefficient of determination $\left(\mathrm{R}^{2}\right)$ of the regression equation. 


\subsection{Dependent variable (PKM)}

The daily kilometrage per person is used as the dependent variable. The data source is the Travel Behaviour Survey for Flanders (OVG3) (Janssens et al., 2009). OVG3 is a mobility survey conducted during 2007-2008 in 8,800 respondents over the age of 6 years and living in the Flanders region (excluding the Brussels Capital Region). The selection is based on a sample from the national register. The home address of the respondents is recorded. Respondents are asked to keep track of all their trips during a predetermined random day by means of a travel diary. Of the 8,800 respondents, 7,273 have actually moved on that day, and have reported the perceived distance covered by their trips. In our analysis we use the sum of the lengths of all trips reported by the respondent. Because of the nature of the data possible biases inherent in the use of travel diaries should be taken into account (Witlox, 2007).

For the sake of calculating the values of the explanatory spatial variables address data was geocoded (converted into XY coordinates) using the Google Maps web service. An overview of the residential locations of the respondents is given by Fig. 1.

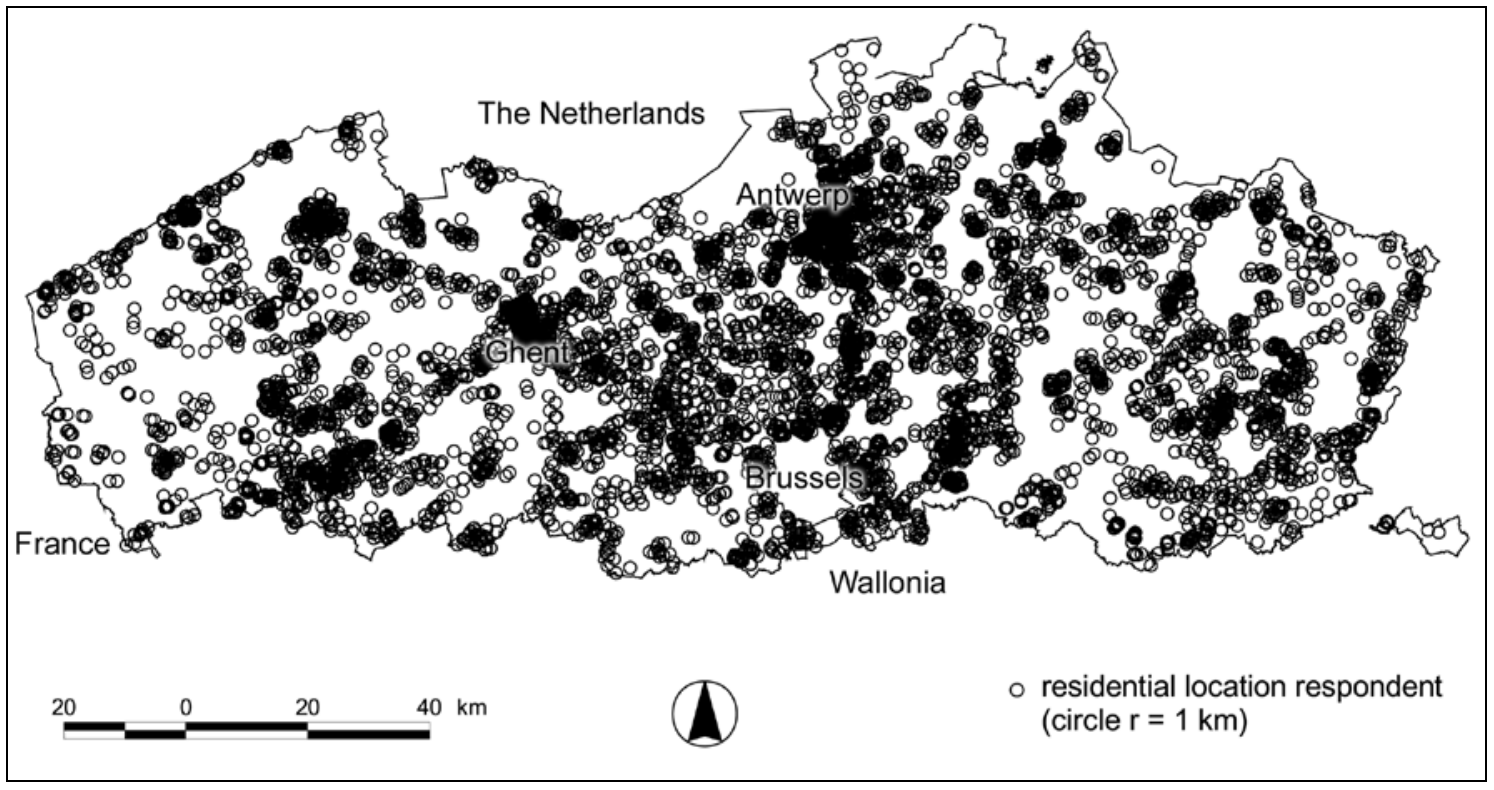

Fig. 1: Situation of the residential location of the respondents in the study area 


\subsection{Explanatory variables}

A total of six explanatory variables have been selected (in addition to the control variables, which are discussed subsequently), each of which can be considered as a measure for the mutual spatial proximity with regard to potential destinations. The variables are: (i) accessibility, (ii) residential density, (iii) land use diversity, (iv) job density, (v) minimum commuting distance, and (vi) proximity of facilities. The construction of these variables is explained in the following paragraphs.

Since we are using spatially aggregated data, the modifiable areal unit problem (MAUP) (Openshaw and Taylor, 1979) should be taken into account. To reduce distortion of the results by the influence of the spatial scale at which data is aggregated, each variable has been determined at three different levels of aggregation. To this end, per respondent three circular zones have been drawn of which the midpoint is the reported residential location, with a respective radius equalling $1 \mathrm{~km}, 4 \mathrm{~km}$ and $8 \mathrm{~km}$. Although the choice of these three levels may seem rather arbitrary, the analysis will clearly show that the used variables do only have clear impact at the lowest scale level. Consequently, the two higher aggregation levels will be removed from the regression, thus avoiding multicollinearity problems. At the other hand, given the resolution of the basic data sets, using an even smaller zone than a circle with $r=1 \mathrm{~km}$ would not be justified.

Within these circles, data is then averaged on the basis of the proportional overlap with the original zones associated with the used data sets (these are census wards, traffic analysis zones (TAZ's) and a one kilometre square grid respectively).

\subsubsection{Accessibility $(A C C)$}

To define regional geographical accessibility, we start from the 2007 population data in Flanders and Brussels, aggregated by census ward. A distance matrix is calculated between each possible pair of census wards, based on a shortest path calculation over the road network (Streetnet). Finally, for each census ward, the total distance that should be covered to visit each resident of any other census ward in the study area once and return back home, is summed. This accessibility index thus gives a measure of the interaction opportunities with all other inhabitants of Flanders and Brussels, based on physical distance. 
A disadvantage of this measure is that neighbouring countries and regions are not accounted for. However, the nature of a cumulative accessibility measure requires a clear delineation of the study area. The applied boundary is justified by rather strong language and cultural differences making daily travel crossing the outer borders of the Flanders region relatively rare. For example, in 2007, only 2.0\% of Flanders' employed labour force worked in Wallonia and only 1.5\% worked abroad. (Policy Research Centre on Work and Social Economy, 2010) Also, since this is a distance based accessibility measure, it does not take into account variations in travel speed e.g. due to choice options in travel mode and route, or the presence of congestion.

\subsubsection{Residential Density $(P O P D)$}

The residential density is based on government population data for 2007 , aggregated by census ward in Flanders.

\subsubsection{Land use diversity (DIV)}

To approximate the degree of land use mix, the Strucnet file of the National Geographical Institute of Belgium (2009) was used, containing all buildings that are represented by the official topographic maps with scale 1:10,000. The buildings are divided into categories. Although the accuracy of the categorization is limited, this inventory can be used to calculate approximate land use diversity in a given area. Since this dataset contains a functional classification and is available at a high resolution, it prevails on satellite imagery and is thus the best area covering dataset currently available.

To calculate spatial-functional diversity, we employ the Shannon index. This index is used in landscape ecology as a measure of morphological diversity (Nagendra, 2002), and is sometimes called spatial entropy (Batty, 1974). The calculation was done for a square grid based on an area of $1 \mathrm{~km}^{2}$, after which results were proportionally aggregated within the three described circular zones. In this way, the possible additional bias caused by the property of the Shannon index to increase with larger area coverage is avoided.

3.3.4. Job density $(J O B D)$ 
Job density is based on commuting data as provided by the Multimodal Model for Flanders (MMM, version 2007). MMM is a simulation of all personal trips in the Flanders region formatted as an origin-destination (OD) matrix and is based on a combination of various sources of socio-economic data. MMM aggregates arrivals of all commuting trips between 4 am and 11 am in the morning traffic within TAZ's, which are comparable to, but typically slightly larger than, census wards.

\subsubsection{Minimum commuting distance $(M C D)$}

This variable was constructed based on the OD-matrices for commuting between 4 am and $11 \mathrm{am}$, as they were simulated in the MMM. The principle of the method implies that any departure (in this case in the morning traffic) is linked to the nearest possible arrival (also in the morning traffic). Per TAZ, the number of departures, as well as the number of arrivals are retained, but the in reality existing tie between origins and destinations is cut in order to minimize the total distance travelled within the system. This theoretical exercise provides a good measure of the spatial proximity between the housing market and the labour market. The data are results provided by Boussauw et al. (2011c), where details on the calculation can be found.

\subsubsection{Proximity to facilities (SPROX)}

This variable was constructed based on the spatial distribution of non-work related destinations that are often visited by an average Flemish household, such as schools, shops, cafes, sports clubs, banks, medical services, et cetera. Per census ward the minimum distance was calculated that needs to be covered by an average Flemish family to get its weekly programme done when always opting for the closest facility within each destination class. This weekly programme for an average family was determined based on data from the second phase of the Travel Behaviour Survey for Flanders (OVG2) (Zwerts et al., 2004). The data are results provided by Boussauw and Witlox (2010), to which we refer for further calculation details.

\subsection{Control variables}

The OVG3 (Janssens et al., 2009) contains a number of socio-economic data that may explain part of the variance in the reported distance. These variables are: education level $(E D U)$, income level $(I N C)$, age $(A G E)$ and gender $(G N D)$. We 
include these in the model as control variables. This means that our research does not focus on the explanatory power of these socio-economic variables, although it is supposed that they make the regression equation more fitting. The selected control variables all exhibit a statistically significant relationship with the reported travel distance and make an important contribution to the model fit.

Education and income levels are included as continuous variables. Because of the assumed non-linear influence of the respondent's age, the age variable is recoded into four dummy variables. Following categories are considered: 0-19 years, 20-39 years, 40-59 years and 60-79 years, while 80 years or older is used as the reference category. Gender is obviously a dummy variable; male is considered as the reference group.

\section{Analysis}

Based on the described variables, a multivariate linear regression equation has been framed. A logarithmic transformation was applied on the dependent variable $P K M$, resulting in an adequate approximation of the normal distribution. After an exploratory test for the presence of non-linear relationships, a linear regression appeared to provide the best match with reality if the non-linear effect of the age of the respondent is modelled by means of dummy variables. As mentioned, the six explanatory variables were repeatedly constructed at three separate levels of aggregation (circles with $r=1 \mathrm{~km}, r=4 \mathrm{~km}$ and $r=8 \mathrm{~km}$ ). Ultimately, the basic equation is composed of eighteen independent variables and four control variables, and is expressed formally:

$$
\begin{aligned}
\log _{e}(P K M)=\alpha & +\sum_{r=1,4,8} \beta_{1 r} \cdot A C C_{r}+\sum_{r=1,4,8} \beta_{2 r} \cdot P O P D_{r}+\sum_{r=1,4,8} \beta_{3 r} \cdot D I V_{r} \\
& +\sum_{r=1,4,8} \beta_{4 r} \cdot J O B D_{r}+\sum_{r=1,4,8} \beta_{5 r} \cdot M C D_{r}+\sum_{r=1,4,8} \beta_{6 r} \cdot S P R O X_{r} \\
& +\gamma_{1} \cdot A G E_{0-19}+\gamma_{2} \cdot A G E_{20-39}+\gamma_{3} \cdot A G E_{40-59}+\gamma_{4} \cdot A G E_{60-79} \\
& +\gamma_{5} \cdot G N D+\gamma_{6} \cdot E D U+\gamma_{7} \cdot I N C+\mathcal{E}
\end{aligned}
$$

For most spatial variables, no significant effects are yielded. In particular, those variables that are constructed on the same basis but at a different level of aggregation 
(e.g., $A C C_{1}, A C C_{4}$ and $A C C_{8}$ ) appear to be highly correlated and thus causing effects of multicollinearity. The best results are achieved by applying only the first level of aggregation (circles with $r=1 \mathrm{~km}$ ). Subsequently the variables related to the spatial distribution of jobs $\left(J O B D_{1}\right.$ and $\left.M C D_{1}\right)$ do not significantly affect the results. Although this outcome is unexpected, it can be explained by the small proportion of today's commuter traffic in the total number of trips $(20.6 \%)$ and total distance travelled (34.5\%) (Janssens et al., 2009). Also the accessibility variable $A C C_{1}$ was excluded from the equation, since no significant correlation between $A C C_{1}$ and $\log _{e}(P K M)$ was found. The purified regression equation is as follows:

$$
\begin{aligned}
\log _{e}(P K M)= & \alpha+\beta_{1} \cdot P O P D_{1}+\beta_{2} \cdot D I V_{1}+\beta_{3} \cdot \operatorname{SPROX}_{1} \\
& +\gamma_{1} \cdot A G E_{0-19}+\gamma_{2} \cdot A G E_{20-39}+\gamma_{3} \cdot A G E_{40-59}+\gamma_{4} \cdot A G E_{60-79} \\
& +\gamma_{5} \cdot G N D+\gamma_{6} \cdot E D U+\gamma_{7} \cdot I N C+\varepsilon
\end{aligned}
$$

\begin{tabular}{|c|c|c|}
\hline $\mathrm{R}^{2}=0.143$ & coefficient & p-value \\
\hline (constant) & 1.502 & 0.000 \\
\hline$P O P D_{1}$ & $-3.99 \cdot 10^{-5}$ & 0.000 \\
\hline$D I V_{1}$ & -0.278 & 0.001 \\
\hline $\mathrm{SPROX}_{1}$ & 0.004 & 0.000 \\
\hline$A G E_{0-19}$ & 0.847 & 0.000 \\
\hline$A G E_{20-39}$ & 1.066 & 0.000 \\
\hline$A G E_{40-59}$ & 0.969 & 0.000 \\
\hline$A G E_{60-79}$ & 0.624 & 0.000 \\
\hline GND & -0.245 & 0.000 \\
\hline$E D U$ & 0.173 & 0.000 \\
\hline$I N C$ & 0.111 & 0.000 \\
\hline
\end{tabular}

The results of the regression analysis are given in Table 1.

Table 1: Coefficients of the regression analysis

The results are consistent with the literature: significances are satisfactory (all results are within the 0.01 confidence level) at a low coefficient of determination $\left(\mathrm{R}^{2}=\right.$ 14.3\%). The relationships found meet the expectations. A higher population density and a higher degree of spatial diversity are associated with shorter travel distances. Also, a larger minimum distance to reach daily facilities is associated with shorter real travel distances. The age group between 20 and 59 years exhibits the most 
intensive travel pattern, while women are less mobile than men. Both a higher level of education and a higher income are associated with increased mobility.

The relatively small share of the observed variance that is explained by the model, is common for mobility research. Although this phenomenon is in part due to data deficiencies (including underreporting and randomization of reporting days), the truth lies perhaps in the importance of the many random factors that form the underlying reason for a significant share of individual trips, but are difficult or even impossible to model. An example of this is the so-called random taste variation that is accounted for in many discrete choice modelling techniques (Train, 2003, p. 46). In Flanders, we find similar difficulties in travel behaviour modelling attempts in Witlox and Tindemans (2004).

If we redo the regression analysis on the basis of only the control variables, then we obtain an $\mathrm{R}^{2}$ equalling $11.9 \%$. The same analysis based on only the spatial variables yields an $\mathrm{R}^{2}$ of $2.1 \%$. This means that within this last, reduced, model only $2.1 \%$ of the observed variance in distance travelled could be explained by characteristics of spatial proximity of the residential environment of the respondent. As explained in the introduction, this is the restrictive but nevertheless relevant context within which the results should be interpreted.

The sum of the two coefficients of determination of both reduced models is less than $14.3 \%$, which indicates the occurrence of suppression and suggests that combining the two sets of explanatory variables (socio-economic and spatial) indeed yields some added value. However, it is clear that the explanatory value of spatial variables largely subordinates to that of the socio-economic variables. This means, for example, that lowering the average income would be more effective in combating excessive mobility than increasing housing density.

\section{Forecasting model for Flanders}

In order to develop a forecasting, area covering, model based on the results of the regression analysis, we isolate the spatial variables. To this end, the control variables are made constant by equalling these to the mean value of the considered variable in the dataset. Formally: 


$$
\begin{aligned}
\alpha_{c t r l}= & 1.502+0.847 \cdot \overline{A G E_{0-19}}+1.066 \cdot \overline{A G E_{20-39}}+0.969 \cdot \overline{A G E_{40-59}}+0.624 \cdot \overline{A G E_{60-79}} \\
& -0.245 \cdot \overline{G N D}+0.173 \cdot \overline{E D U}+0.111 \cdot \overline{I N C}=3.133
\end{aligned}
$$

Based on the regression coefficients for the spatial variables the expected amount of generated kilometres per inhabitant $P K M_{w}$ for each census ward in Flanders $w$ is determined as follows:

$$
P K M_{w}=\exp \left(3.133-0.0000399 \cdot P O P D_{w}-0.278 \cdot D I V_{w}+0.004 \cdot S P R O X_{w}\right)
$$

The mapped result is shown in Fig. 2. The expected amount of daily generated kilometres per inhabitant based on characteristics of spatial proximity and averaged by census ward is approximately normally distributed and is characterized by the values that are shown in Table 2.

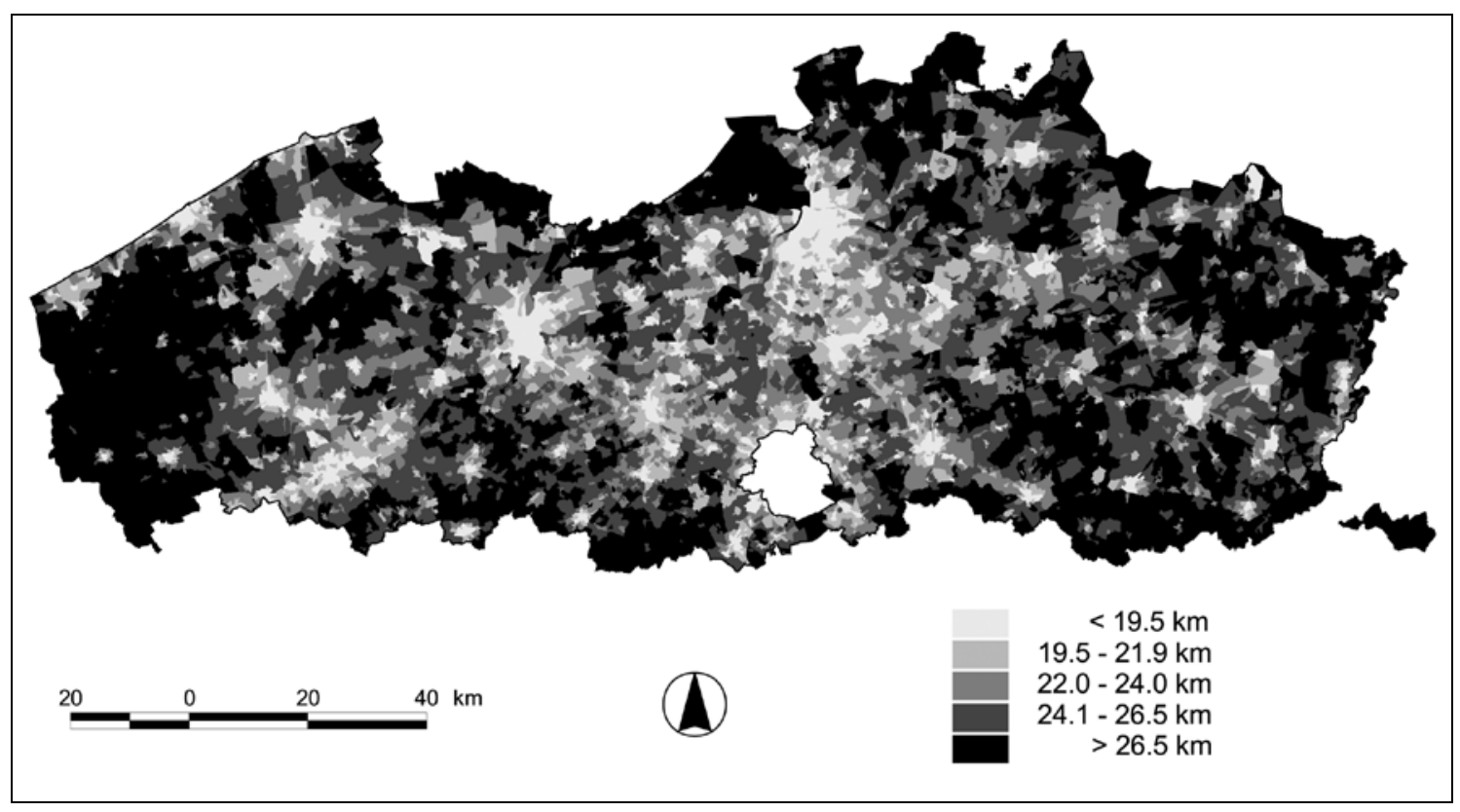

Fig. 2: Spatial distribution of the estimated daily generated mobility per capita based on characteristics of spatial proximity

\begin{tabular}{|l|l|l|l|}
\hline $\mathrm{N}=9205$ & & $\mathrm{~km}$ \\
\hline
\end{tabular}




\begin{tabular}{|l|l|l|l|}
\hline & $\mathrm{Km}$ & $5 \%$ percentile & 15.3 \\
\hline Mean & 23.0 & $25 \%$ percentile & 20.2 \\
\hline Median & 23.0 & $75 \%$ percentile & 25.8 \\
\hline standard deviation & 5.1 & $95 \%$ percentile & 30.1 \\
\hline
\end{tabular}

Table 2: Features of the distribution of daily generated mobility per capita as expected by the model, based on census wards in Flanders

The 95-percentile value is almost twice as large as the 5-percentile value. This means that based on characteristics of spatial proximity, the $5 \%$ best-located census wards are estimated to generate only half of the mobility of the $5 \%$ worst-located wards.

As expected, and as shown in Fig. 2, urban areas yield the lowest values, particularly in the historical city centres and a number of nineteenth-century neighbourhoods in Ghent and Antwerp. Among the regional urban areas mainly Leuven, Mechelen, Aalst, Brugge and Oostende score well. Also the edge of the Brussels conurbation scores quite well, although the agglomeration effect decays rapidly while moving away from the centre of the capital. When we examine regions instead of cities, we see that typically rural areas as well as green and wooded areas with scattered development score badly. Conversely, the immediate vicinity of large agglomerations score well, just as the highly suburbanized areas Kortrijk-Leie (in the south-west) and the so-called Flemish Diamond (the area cornered by Ghent, Antwerp, Leuven and Brussels).

\section{Discussion}

The results can be summarized as follows. Residential density, land use diversity and proximity of facilities affect the daily distance travelled if these variables are measured in the immediate vicinity of the residential location of the respondent (within a radius of $1 \mathrm{~km}$ ). When these variables are aggregated at a higher geographical scale, the impact is no longer significant in most cases. This is also the case for variables that are based on the overall accessibility of the entire population in the study area. From this we can deduce that the overall travel pattern of an average resident of Flanders is to a larger extent determined by local accessibility of possible destinations than by regional accessibility or the embeddedness in the wider region. 
In addition, also variables that are based on the spatial distribution of jobs do not show a significant impact on travel distance. This latter finding is somewhat surprising given the adequate volume of literature that is specifically focusing on the relationship between commuting and the spatial distribution of jobs and housing. A comprehensive overview is given by Horner (2004). Although the commute continues to represent a significant share of overall travel, it should not be forgotten that a large part of the population does not commute. Moreover, the share of the commute in the total traffic volume is systematically decreasing (Pisarski, 2006, p. 2). Also, non-business trips tend to be considerably influenced by the local supply of potential destinations (Handy et al., 2005b), whereas commuting is only limitedly influenced by the local supply of jobs. For the average resident of Flanders, the specific spatial structure of the job market plays a relatively minor role compared to more generalized characteristics of overall spatial proximity.

The results of the regression analysis indicate that only a fraction of the observed variance in distance travelled is explained by spatial features. A combination of some very basic socio-economic characteristics (education, income, age and gender) is already explaining a much larger share of the variance. Nevertheless, both sets of explanatory variables are clearly complementary.

The low proportion of variance explained by a model that contains only spatial variables $\left(\mathrm{R}^{2}=2.1 \%\right)$ entails in practice the risk of neglecting the importance of spatial structure as a framework for the genesis of potentially sustainable travel patterns. However, we argue that the importance of the spatial distribution and thus the mutual distance between potential destinations has decreased in the course of history as the cost of transport fell. The cheaper transport is, the larger individual freedom is in choosing a particular destination from a range of potential locations where the occurred need can be fulfilled. The more expensive transport is, the more often the nearest potential destination will be chosen (Handy et al., 2005b). In the case where transport is expensive, the distance from the residential location to this nearest facility, which is derived from the spatial distribution of the whole range of potential destinations, will largely determine the distance travelled by the considered individual. 
The spatial separation of destinations, a trend which is often designated as "sprawl" is based on a rapid decline in transport costs combined with an increase in travel speed (Ewing, 1994). However, based on the peak oil theory (Witze, 2007), in time, an increase in transport costs is expected due to oil scarcity. Although there is little discussion on the fact that future fossil energy supply will have difficulties in matching global demand, many uncertainties are present. Both the point in time when peak oil will occur and the severity of the economic implications are unclear. In addition, technology that reduces the oil dependence of the transport system, such as the ongoing development and implementation of the electric car, may mitigate these effects (Van Ruijven and Van Vuuren, 2009). However, IEA (2008) estimates that the oil dependence of the global transport system will only drop from 95\% (in 2006) to $92 \%$ in 2030 , mainly through biofuel substitution. So, even after taking into account the development of alternative fuels, it is very likely that the energy component of the cost of transport will gradually increase, with implications for accessibility. Anticipating this by recognizing the principle of spatial proximity in the practice of spatial planning is thus important.

Although much literature has yet emphasized the relationship between spatial characteristics and travel distance, in this paper we have extrapolated the results of the analysis to a model that calculates and visualises in which areas an additional residential unit would contribute the least to mobility growth. Not unexpectedly, the most urbanized areas turn out to be the most resilient and sustainable locations. This means that a further increase of residential density and land use mix in urban areas is the best guarantee for curbing excessive mobility and preparing for the end of cheap oil. However, this conclusion requires some qualification: there are limits to increasing density and land use mix targeted to sustainable mobility patterns, primarily by environmental standards and social desirability (Gordon and Richardson, 1997). Moreover, our results suggest that a policy of compact development - compared to less steered, dispersed development - will yield an only marginal direct impact on the distances travelled. This finding is confirmed by numerous policy studies (e.g. Echenique et al., 2009, p. 81). 


\section{Conclusion and directions for further research}

Although the influence of locally measurable features of spatial structure on the distances travelled by individuals is statistically significant, the explanatory power is small. However, in a context of possibly increasing transport cost, but also of climate policies and congestion problems, this does not mean that the spatial component is unimportant. Moreover, the explanation that is provided by spatial variables is complementary to the variance explained by socio-economic variables.

Using the analysis results in a policy instrument that can be used for steering additional residential development is therefore useful. In order to keep undesired mobility growth within certain limits, it is appropriate to strengthen the urban character of existing cities as much as possible.

However, it is still possible to improve the model based on spatial and functional disaggregation. This would enable the development of more accurate sub-models that are optimized for one city or a part of a region, or for one category of travel (e.g. the commute), or for one section of the population (e.g. school children). Moreover, a refinement would not only allow modelling the spatial distribution of residential locations, but also of destination categories such as schools, jobs, shops or public services.

\section{Acknowledgements}

This research has been made possible within the Flemish Policy Research Centre for Housing and Space, funded by the Ministry of the Flemish Community. Also, we would like to thank the two anonymous referees for their useful comments. All remaining errors are ours.

\section{References}

Batty, M., 1974. Spatial entropy. Geographical Analysis 6, 1-31.

Boussauw, K., Neutens, T., Witlox, F., 2011a. "Relationship between spatial proximity and travel-to-work distance: The effect of the compact city." Regional Studies. in press. 
Boussauw, K., Derudder B., Witlox, F., 2011b. Measuring spatial separation processes through the minimum commute: The case of Flanders. European Journal of Transport and Infrastructure Research 11(1). in press.

Boussauw, K., Neutens, T., Witlox, F., 2011c. Minimum commuting distance as a spatial characteristic in a non-monocentric urban system: the case of Flanders. Papers in Regional Science 90(1). in press.

Boussauw, K., Witlox, F., 2009. Introducing a commute-energy performance index for Flanders. Transportation Research Part A 43(5), 580-591.

Boussauw, K., Witlox, F., 2010. Excess travel in non-commuting trips: a regional case study. Lisbon: Proceedings of the World Conference on Transport Research.

Cervero, R., 1996. Mixed land-uses and commuting: Evidence from the American housing survey. Transportation Research Part A, 30(5), 361-377.

Cervero, R., Kockelman, K., 1997. Travel demand and the 3Ds: Density, diversity, and design. Transportation Research Part D, 2(3), 199-219.

Dodson, J., Sipe, N., 2008. Shocking the suburbs: urban location, homeownership and oil vulnerability in the Australian city. Housing Studies, 23(3), 377-401.

Echenique, M., Hargreaves, A., Jin, Y., Mitchell, G., Namdeo, A., 2009. London and the Wider South East Regions Case Study. Cambridge-London-Bristol: Solutions Project.

Ewing, R., Bartholomew, K., Winkelman, S., Walters, J., Chen, D., 2008. Growing Cooler: The Evidence on Urban Development and Climate Change. Washington DC: Urban Land Institute.

Ewing, R., Cervero, R., 2010. Travel and the built environment: a meta-analysis. Journal of the American Planning Association, 76(3), 265-294.

Ewing, R., 1994. Characteristics, causes, and effects of sprawl: a literature review. Environmental and Urban Studies, 21(2), 1-15.

Giuliano, G., 1995. The weakening transportation-land use connection. Access, 6(1), 3-11.

Gordon, P., Richardson, H. W., 1997. Are compact cities a desirable planning goal? Journal of the American Planning Association, 63(1), 95-106.

Handy, S., Cao, X., Mokhtarian, P., 2005a. Correlation or causality between the built environment and travel behavior? Evidence from Northern California. Transportation Research Part D, 10(6), 427-444. 
Handy, S., Weston, L., Mokhtarian, P., 2005b. Driving by choice or necessity? Transportation Research Part A, 39(2-3), 183-203.

Horner, M. W., 2004. Spatial dimensions of urban commuting: A review of major issues and their implications for future geographic research. The Professional Geographer, 56(2), 160-173.

IEA, 2008. World Energy Outlook. Paris: International Energy Agency.

Janssens, D., Moons, E., Nuyts, E., Wets, G., 2009. Onderzoek Verplaatsingsgedrag Vlaanderen 3 (2007-2008). Brussel-Diepenbeek: Universiteit Hasselt.

Maat, K., Timmermans, H., 2006. Influence of land use on tour complexity. Transportation Research Record, 1977, 234-241.

Mees, P., 2010. Transport for Suburbia: Beyond the Automobile Age. London: Earthscan.

Mindali, O., Raveh, A., Salomon, I., 2004. Urban density and energy consumption: a new look at old statistics. Transportation Research Part A, 38(2), 143-162.

Naess, P., 2003. Urban structures and travel behaviour. Experiences from empirical research in Norway and Denmark. European Journal of Transport and Infrastructure Research, 3(2), 155-178.

Naess, P., Sandberg, S. L., 1996. Workplace location, modal split and energy use for commuting trips. Urban Studies, 33(3), 557-580.

Nagendra, H., 2002. Opposite trends in response for the Shannon and Simpson indices of landscape diversity. Applied Geography, 22, 175-186.

National Geographical Institute of Belgium, 2009. Structuur en codering van de gegevens top10v-gis en top50V-gis. National Geographical Institute of Belgium from http://www.ngi.be/Common/articles/CA_Top10V-GIS_TOP50VGIS/restruct_doc_nl.htm.

Newman, P., Kenworthy, J., 1989. Cities and Automobile Dependence. A Sourcebook. Aldershot: Gower.

Newman, P., Kenworthy, J., 1999. Sustainability and Cities: Overcoming Automobile Dependence. Washington, DC: Island Press.

Openshaw, S., Taylor, P., 1979. A Million Or So Correlation Coefficients: Three Experiments on the Modifiable Areal Unit Problem. In: Wrigley, N., (Ed), Statistical Methods in the Spatial Sciences. London: Routledge and Kegan Paul, pp. 127-144. 
Pisarski, A. E., 2006. Commuting in America III. Washington DC: Transportation Research Board.

Policy Research Centre on Work and Social Economy, 2010. Gewestelijke uitgaande pendel. Policy Research Centre on Work and Social Economy from http://www.steunpuntwse.be/view/nl/18767. Retrieved 06/08/2010.

Rietveld, P., Vickerman, R., 2004. Transport in regional science: The "death of distance" is premature. Papers in Regional Science, 83(1), 229-248.

Schafer, A., 2000. Regularities in travel demand: An international perspective. Journal of Transportation and Statistics, 3(3), 1-31.

Train, K., 2003. Discrete Choice Methods with Simulation. Cambridge, UK: University Press.

Van Acker, V., Witlox, F., 2011. Commuting trips within tours: How is commuting related to land use? Transportation, doi: 10.1007/s11116-010-9309-6.

Van Ruijven, B., Van Vuuren, D. P. 2009. Oil and natural gas prices and greenhouse gas emission mitigation. Energy Policy, 37(11), 4797-4808.

Verhetsel, A., Thomas, I., Beelen, M. 2010. Commuting in Belgian metropolitan areas: The power of the Alonso-Muth model. Journal of Transport and Land Use, 2(3), 109-131.

Wegener, M., 2010. The future of mobility in cities: Challenges for urban modelling. Lisbon: Proceedings of the World Conference on Transport Research.

Witlox, F., 2007. Evaluating the reliability of reported distance data in urban travel behaviour analysis. Journal of Transport Geography, 15(3), 172-183.

Witlox, F., Tindemans, H., 2004. The application of rough sets analysis in activitybased modelling. Opportunities and constraints. Expert Systems with Applications, 27(4), 585-592.

Witze, A., 2007. That's oil, folks.... Nature, 445(4), 14-17.

Zwerts, E., Nuyts, E., 2004. Onderzoek Verplaatsingsgedrag Vlaanderen 2000-2001. Brussels-Diepenbeek: Ministry of the Flemish Community. 